\title{
Active $\mathrm{Er}^{3+}$ doped lead-niobium-germanate planar waveguides produced by pulsed laser deposition
}

\author{
R. Balda ${ }^{\text {a,b,c * }}$, O. Sanz ${ }^{\text {d }}$ J. Gonzalo ${ }^{\text {d }}$, M. Jiménez de Castro ${ }^{\mathrm{d}}$, A. Perea ${ }^{\mathrm{d}}$, J.M. Fernández-Navarro ${ }^{\mathrm{d}}$, \\ C.N. Afonso ${ }^{\mathrm{d}}$, and J. Fernández $\mathrm{z}^{\mathrm{a}, \mathrm{b}, \mathrm{c}}$ \\ ${ }^{a}$ Dpto. Fisica Aplicada I, Escuela Superior de Ingenieros, Alda. Urquijo s/n 48013 Bilbao, Spain \\ ${ }^{\mathrm{b}}$ Centro Mixto CSIC-UPV/EHU and ${ }^{\mathrm{c} D I P C}$, Donostia, Spain \\ ${ }^{\mathrm{d}}$ Instituto de Óptica, CSIC, Serrano 121, 28006 Madrid, Spain
}

\begin{abstract}
In this work, pulsed laser deposition has been used to produce $\mathrm{Er}^{3+}$ doped lead-niobium-germanate thin films from $\mathrm{Er}^{3+}$ doped $50 \mathrm{GeO}_{2}-25 \mathrm{PbO}-25 \mathrm{Nb}_{2} \mathrm{O}_{5}$ transparent glasses with an $\mathrm{Er}_{2} \mathrm{O}_{3}$ content in the $0.5-3$ weight $\%$ range. In all cases, by pumping the ${ }^{4} \mathrm{I}_{11 / 2}$ level of $\mathrm{Er}^{3+}$, the as deposited films are optically active showing at room temperature the ${ }^{4} \mathrm{I}_{13 / 2} \rightarrow{ }^{4} \mathrm{I}_{15 / 2}$ emission centered around $1530 \mathrm{~nm}$. The luminescence intensity increases as the $\mathrm{Er}^{3+}$ content in the targets increases, whereas the opposite behavior is observed for the luminescence lifetime. The emission intensity and lifetimes of the 1.5 $\mu \mathrm{m}$ emission increase upon annealing.
\end{abstract}

Keywords: Heavy metal oxide glasses, thin films, erbium, Pulsed Laser Deposition

\section{INTRODUCTION}

Heavy metal oxide (HMO) glasses are characterized by a high content of heavy metals such as Bi or Pb. They have high linear (>2) and nonlinear (up to $10^{2}$ times that of silicate glasses) refractive index and a broad transparence range from the visible up to the mid infrared $(0.4<\lambda<8 \mu \mathrm{m})$ [1-3]. The broad transparence range in the mid-IR is related to a phonon energy that is the lowest among all the oxide glasses $\left(\sim 800 \mathrm{~cm}^{-1}\right)$ [4]. This low phonon energy is in addition essential to achieve longer lifetimes and better quantum efficiency of the luminescence in the case of rare earth doped glasses [5]. All these properties make HMO glasses very attractive for photonic applications such as ultra-low loss optical waveguides in the 2.5-3.0 $\mu \mathrm{m}$ range, and more efficient gain or nonlinear optical devices [1-3,5].

Among HMO glasses, lead-germanate based glasses combine high mechanical strength, chemical durability, and temperature stability with good IR transmission up to $4.5 \mu \mathrm{m}$, thus making them promising materials for the development of new lasing materials, upconverting phosphors, and optical waveguides [6,7]. Nevertheless, the production of these materials by thin film techniques for the development of integrated optic devices is still a challenge.

In this work, pulsed laser deposition (PLD) has been used to produce $\mathrm{Er}^{3+}$ doped lead-niobium-germanate thin films from $\mathrm{Er}^{3+}$ doped $50 \mathrm{GeO}_{2}-25 \mathrm{PbO}-25 \mathrm{Nb}_{2} \mathrm{O}_{5}(\mathrm{GPN})$ transparent glasses with an $\mathrm{Er}_{2} \mathrm{O}_{3}$ content in the 0.5-3 weight \% range. In all cases, by pumping the ${ }^{4} \mathrm{I}_{11 / 2}$ level of $\mathrm{Er}^{3+}$, the as deposited films are optically active showing at room temperature the ${ }^{4} \mathrm{I}_{13 / 2} \rightarrow{ }^{4} \mathrm{I}_{15 / 2}$ emission centered around $1530 \mathrm{~nm}$. Results on the $\mathrm{Er}^{3+}$ fluorescence spectra and lifetimes after annealing are also included.

*Corresponding author: e-mail: wupbacrr@bi.ehu.es, Phone: 34-94 601 4051, Fax: 34-94 6014178. 


\section{SPECTROSCOPIC PROPERTIES OF GPN:Er ${ }^{3+}$ GLASSES}

The HMO glasses selected for this work belong to the $\mathrm{GeO}_{2}-\mathrm{PbO}-\mathrm{Nb}_{2} \mathrm{O}_{5}$ ternary system in which $\mathrm{GeO}_{2}$ acts as a glass former that stabilizes the vitreous matrix whereas $\mathrm{Nb}_{2} \mathrm{O}_{5}$ helps to increase the linear and nonlinear refractive index, the thermal stability, and the chemical durability of the glass. Bulk samples with different nominal compositions were prepared in batches of $20 \mathrm{~g}$. by mixing high-purity reagents: $\mathrm{GeO}_{2}(99.999 \%), \mathrm{PbO}(99.9995 \%), \mathrm{and}^{\mathrm{Nb}} \mathrm{O}_{5}$ $(99.999 \%)$. Each mixture was placed in a platinum crucible and melted in a furnace at a temperature of $1100-1300{ }^{\circ} \mathrm{C}$ for $1 \mathrm{~h}$, then poured onto a brass plate, followed by $1 \mathrm{~h}$ of annealing at $450{ }^{\circ} \mathrm{C}$ and then cooled down to room temperature at $1.5{ }^{\circ} \mathrm{C} / \mathrm{min}$. The composition of the bulk samples was $50 \mathrm{GeO}_{2}-25 \mathrm{PbO}-25 \mathrm{Nb}_{2} \mathrm{O}_{5}$. These samples were doped with $0.5,1,2$, and $3 \mathrm{wt} \%$ of $\mathrm{Er}_{2} \mathrm{O}_{3}$.

The room temperature absorption spectra were obtained for all samples in the 300-1700 nm range with a Cary 5 spectrophotometer. As an example, Fig. 1 shows the absorption coefficient as a function of wavelength for the sample doped with $2 \%$ of $\mathrm{Er}_{2} \mathrm{O}_{3}$. The inhomogeneously broadened bands are assigned to the transitions from the ${ }^{4} \mathrm{I}_{15 / 2}$ ground state to the excited states of $\mathrm{Er}^{3+}$ ions. The spectra obtained for the other samples are similar, except for the band intensities, which are dependent on the $\mathrm{Er}^{3+}$ concentration. The integrated absorption coefficient for different absorption bands shows a linear dependence on concentration, which indicates that the relative concentrations of $\mathrm{Er}^{3+}$ ions are in agreement with the nominal values.

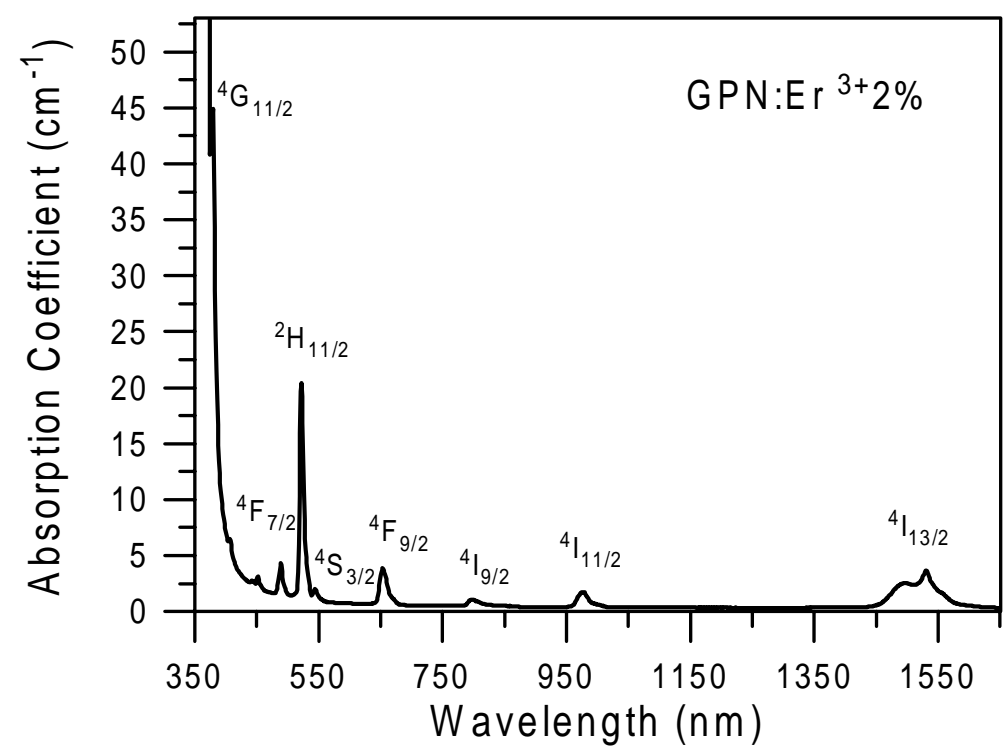

Figure 1. Room temperature absorption spectrum of GPN:Er ${ }^{3+}(2 \%)$ glass.

Data from the spectrum in Fig. 1, together with the values of the refractive index $(\mathrm{n}=2.1137)$ and the $\mathrm{Er}^{3+}$ concentration $\left(3.44 \times 10^{20} \mathrm{~cm}^{-3}\right)$ have been used to calculate the radiative transition rates by using the Judd-Ofelt (JO) theory [8,9]. The absorption bands measured are all dominated by electric-dipole transitions except the ${ }^{4} \mathrm{I}_{15 / 2} \rightarrow{ }^{4} \mathrm{I}_{13 / 2}$ transition, which contains electric-dipole and magnetic-dipole contributions. The magnetic-dipole contribution, $\mathrm{f}_{\mathrm{md}}$, can be obtained from the equation $\mathrm{f}_{\mathrm{md}}=\mathrm{nf}^{\prime}$ [10], where $\mathrm{n}$ is the refractive index of the glass and $\mathrm{f}^{\prime}$ is a quantity which was calculated on the basis of energy-level parameters for lanthanide aquo ions. The electric-dipole oscillator strength for this transition is then obtained by subtracting the calculated magnetic-dipole contribution from the experimental oscillator strength. By using a least squares fitting of calculated and experimental oscillator strengths, the JO parameters obtained for this glass are $\Omega_{2}=6.64 \times 10^{-20} \mathrm{~cm}^{2}, \Omega_{4}=1.52 \times 10^{-20} \mathrm{~cm}^{2}$, and $\Omega_{6}=0.97 \times 10^{-20} \mathrm{~cm}^{2}$, with a root-mean-squared deviation equal to $2.62 \times 10^{-7}$. These values are in agreement with those previously reported in binary lead-germanate glasses [11] and in lead-tellurium germanate based glasses [12]. 
The radiative transition probabilities for all excited levels of $\mathrm{Er}^{3+}$ can be calculated by using the JO parameters. The radiative transition probability is given by [13],

$$
\mathrm{A}\left[(\mathrm{S}, \mathrm{L}) \mathrm{J} ;\left(\mathrm{S}^{\prime} \mathrm{L}^{\prime}\right) \mathrm{J}^{\prime}\right]=\frac{64 \pi^{4} \mathrm{e}^{2}}{3 \mathrm{~h} \lambda^{3}(2 \mathrm{~J}+1)}\left[\mathrm{n} \frac{\left(\mathrm{n}^{2}+2\right)^{2}}{9} \mathrm{~S}_{\mathrm{ed}}+\mathrm{n}^{3} \mathrm{~S}_{\mathrm{md}}\right]
$$

where $\mathrm{n} \frac{\left(\mathrm{n}^{2}+2\right)^{2}}{9}$ is the local field correction for electric dipole transitions and $\mathrm{n}^{3}$ for magnetic dipole transitions.

The radiative lifetime is related to radiative transition probabilities by,

$$
\tau_{\mathrm{R}}=\left\{\sum_{\mathrm{S}^{\prime}, \mathrm{L}^{\prime}, \mathrm{J}^{\prime}} \mathrm{A}\left[(\mathrm{S}, \mathrm{L}) \mathrm{J} ;\left(\mathrm{S}^{\prime}, \mathrm{L}^{\prime}\right) \mathrm{J}^{\prime}\right]\right\}^{-1}
$$

The fluorescence branching ratio can be obtained from the transition probabilities by using,

$$
\beta\left[(\mathrm{S}, \mathrm{L}) \mathrm{J} ;\left(\mathrm{S}^{\prime}, \mathrm{L}^{\prime}\right) \mathrm{J}^{\prime}\right]=\frac{\mathrm{A}\left[(\mathrm{S}, \mathrm{L}) \mathrm{J} ;\left(\mathrm{S}^{\prime}, \mathrm{L}^{\prime}\right) \mathrm{J}^{\prime}\right]}{\sum_{\mathrm{S}^{\prime}, \mathrm{L}^{\prime}, \mathrm{J}^{\prime}} \mathrm{A}\left[(\mathrm{S}, \mathrm{L}) \mathrm{J} ;\left(\mathrm{S}^{\prime}, \mathrm{L}^{\prime}\right) \mathrm{J}^{\prime}\right]}
$$

The radiative transition probabilities, the branching ratios, and the radiative lifetimes of $\mathrm{Er}^{3+}$ in GPN glass are shown in Table 1.

Table 1. Predicted radiative transition rates, lifetimes, and branching ratios of $\mathrm{Er}^{3+}$ in GPN glass.

\begin{tabular}{rcccc}
\hline Transitions & Energies $\left(\mathrm{cm}^{-1}\right)$ & $\mathrm{A}_{\text {rad }}\left(\mathrm{s}^{-1}\right)$ & $\tau_{\text {rad }}(\mathrm{ms})$ & $\beta(\%)$ \\
\hline${ }^{4} \mathrm{I}_{13 / 2} \rightarrow{ }^{4} \mathrm{I}_{15 / 2}$ & 6597 & 240.9 (e.d.) & 3.07 & 100 \\
& & 84.2 (m.d.) & & \\
${ }^{4} \mathrm{I}_{11 / 2} \rightarrow{ }^{4} \mathrm{I}_{15 / 2}$ & 10212 & 351.6 & 2.45 & 86.3 \\
${ }^{4} \mathrm{I}_{13 / 2}$ & 3622 & $36(\mathrm{e} . \mathrm{d})$. & & 13.7 \\
& & 18.8 (m.d.) & & \\
${ }^{4} \mathrm{I}_{9 / 2} \rightarrow{ }^{4} \mathrm{I}_{15 / 2}$ & 12433 & 309.4 & 2.47 & 76.5 \\
${ }^{4} \mathrm{I}_{13 / 2}$ & 5843 & 89.9 & & 22.3 \\
${ }^{4} \mathrm{I}_{11 / 2}$ & 2221 & $2.6(\mathrm{~m} . \mathrm{d})$. & & 1.2 \\
${ }^{4} \mathrm{~F}_{9 / 2} \rightarrow{ }^{4} \mathrm{I}_{15 / 2}$ & 15243 & 3296.5 & 0.275 & 90.6 \\
${ }^{4} \mathrm{I}_{13 / 2}$ & 8656 & 178.3 & & 4.9 \\
${ }^{4} \mathrm{I}_{11 / 2}$ & 5034 & 152.1 & & 4.18 \\
${ }^{4} \mathrm{I}_{9 / 2}$ & 2813 & 10.3 & & 0,28 \\
${ }^{4} \mathrm{~S}_{3 / 2} \rightarrow{ }^{4} \mathrm{I}_{15 / 2}$ & 18324 & 2403.8 & 0.279 & 67.1 \\
${ }^{4} \mathrm{I}_{13 / 2}$ & 11737 & 969.1 & & 27 \\
${ }^{4} \mathrm{I}_{11 / 2}$ & 8115 & 77.9 & & 2.17 \\
${ }^{4} \mathrm{I}_{9 / 2}$ & 5893 & 130.4 & & 3.64 \\
${ }^{4} \mathrm{H}_{11 / 2} \rightarrow{ }^{2} \mathrm{I}_{15 / 2}$ & 3080 & 1.55 & & 0.03 \\
& 19088 & 21940.5 & ---- & ----- \\
& & & & \\
\hline
\end{tabular}


The lifetime values of the ${ }^{4} \mathrm{~S}_{3 / 2}$, and ${ }^{4} \mathrm{~F}_{9 / 2}$ levels were obtained at room temperature for different $\mathrm{Er}^{3+}$ concentrations by exciting at $484 \mathrm{~nm}$ with a dye laser pumped by a pulsed nitrogen laser and detecting the emission with a Hamamatsu R928 photomultiplier. Table 2 shows the lifetime values obtained by a fit to a single exponential function. As it can be observed, the lifetime decreases as the concentration increases which indicates that nonradiative energy transfer is present for concentrations higher than $0.5 \%$. Lifetimes were also measured for the ${ }^{4} \mathrm{I}_{11 / 2}$ and ${ }^{4} \mathrm{I}_{13 / 2}$ levels at room temperature by exciting the samples at $803 \mathrm{~nm}$ in the ${ }^{4} \mathrm{I}_{9 / 2}$ level with a Ti-sapphire laser and detecting the emission with a Hamamatsu R5509 photomultiplier. Fast nonradiative relaxation efficiently populates the ${ }^{4} \mathrm{I}_{11 / 2}$ and ${ }^{4} \mathrm{I}_{13 / 2}$ levels. The lifetime of the ${ }^{4} \mathrm{I}_{13 / 2}$ level slightly decreases for concentrations higher than $0.5 \%$.

Table 2. Lifetimes of the ${ }^{4} \mathrm{~S}_{3 / 2},{ }^{4} \mathrm{~F}_{9 / 2},{ }^{4} \mathrm{I}_{11 / 2}$, and ${ }^{4} \mathrm{I}_{13 / 2}$ levels obtained at room temperature.

\begin{tabular}{ccccc}
\hline $\mathrm{Er}_{2} \mathrm{O}_{3} \%$ & $548 \mathrm{~nm}^{4} \mathrm{~S}_{3 / 2}$ & $653 \mathrm{~nm}^{4} \mathrm{~F}_{9 / 2}$ & $980 \mathrm{~nm}^{4} \mathrm{I}_{11 / 2}$ & $1530 \mathrm{~nm}^{4} \mathrm{I}_{13 / 2}$ \\
\hline $0.5 \%$ & $24 \mu \mathrm{s}$ & $25 \mu \mathrm{s}$ & $92.57 \mu \mathrm{s}$ & $3.7 \mathrm{~ms}$ \\
$1 \%$ & $21 \mu \mathrm{s}$ & $21 \mu \mathrm{s}$ & $91.81 \mu \mathrm{s}$ & $3.5 \mathrm{~ms}$ \\
$2 \%$ & $17 \mu \mathrm{s}$ & $15 \mu \mathrm{s}$ & $88.83 \mu \mathrm{s}$ & $3.5 \mathrm{~ms}$ \\
\hline
\end{tabular}

The fluorescence spectrum corresponding to the ${ }^{4} \mathrm{I}_{13 / 2} \rightarrow{ }^{4} \mathrm{I}_{15 / 2}$ was measured at room temperature under excitation at $980 \mathrm{~nm}$. The spectrum has a maximum at 1530 with a FWHM around $88 \mathrm{~nm}$ which is much larger than that of silicabased glasses $(\approx 30-40 \mathrm{~nm})$. A large bandwidth is useful for tunable lasers and also for optical amplifiers to increase the number of optical channels that can be multiplexed without gain compensation techniques in wavelength division multiplexed systems.

The room temperature stimulated emission cross section of the ${ }^{4} \mathrm{I}_{13 / 2} \rightarrow{ }^{4} \mathrm{I}_{15 / 2}$ laser transition has been obtained by using the following expression [14],

$$
\sigma_{\mathrm{se}}=\frac{\lambda_{\mathrm{p}}^{4}}{8 \pi \mathrm{n}^{2} \mathrm{c}} \frac{1}{\tau \Delta \lambda_{\mathrm{eff}}}
$$

where $\lambda_{\mathrm{p}}$ is the peak fluorescence wavelength, $\mathrm{c}$ is the velocity of light, $\mathrm{n}$ the refractive index, and $\Delta \lambda_{\text {eff }}$ is the effective linewidth. The effective linewidth of the transition has been calculated by using the relation $\Delta \lambda_{\text {eff }}=\int \frac{\mathrm{I}(\lambda) \mathrm{d} \lambda}{\mathrm{I}_{\max }}$. The absorption and emission cross-sections are shown in Fig. 2 and the maximum emission cross section is $5.4 \times 10^{-21} \mathrm{~cm}^{2}$.

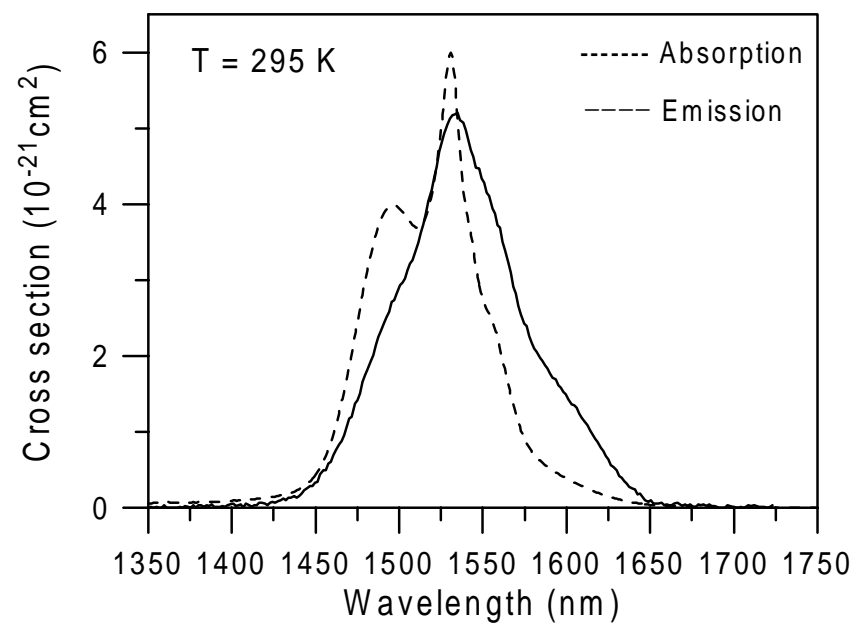

Figure 2. Absorption and emission cross-sections of $\mathrm{Er}^{3+}$ in GPN glass. 


\section{GPN:Er ${ }^{3+}$ THIN FILMS}

$\mathrm{Er}^{3+}$ doped lead-niobium-germanate glassy thin films have been produced by PLD with an ArF excimer laser beam $\left(\lambda=193 \mathrm{~nm}, \tau=20 \mathrm{~ns}\right.$ FWHM) with an energy density of $3 \mathrm{~J} / \mathrm{cm}^{2}$ at an oxygen pressure of $5 \times 10^{-2}$ mbar. The laser beam was focused at an angle of $45^{\circ}$ on the surface of a rotating glass target placed in a vacuum chamber evacuated to a residual pressure of $6 \times 10^{-6}$ mbar. GPN bulk samples both undoped and doped with $0.5,1,2$ and 3 wt $^{2} \mathrm{Er}_{2} \mathrm{O}_{3}$, were used as targets to produce the thin films on chemically cleaned Si (100) wafers in which no attempt to remove the native oxide layer was made and held at at room temperature.

Nuclear microanalysis, by the direct observation of nuclear reactions and backscattered particles has been used to determine the composition of the undoped film. The oxygen content was measured through the nuclear reaction ${ }^{16} \mathrm{O}(\mathrm{d}$, p) ${ }^{17} \mathrm{O}^{*}$ at $0.895 \mathrm{MeV}$, the absolute values being determined within $4 \%$. Cation contents $(\mathrm{Ge}, \mathrm{Nb}, \mathrm{Pb})$ were measured by Rutherford backscattering spectrometry (RBS) with a ${ }^{4} \mathrm{He}^{++}$beam at $5.93 \mathrm{MeV}$. Such a high beam energy was chosen to improve the mass resolution of the experiment. The results obtained from the compositional analysis are summarized in Table 3. The film composition is close to that of the target although the film is slightly oxygen defficient.

Table 3. Relative target and film composition for the glassy films produced from the bulk GPN undoped target. Film and target relative composition will be referred to by the subindexes " $\mathrm{f}$ " and " $\mathrm{t}$ " respectively

\begin{tabular}{cccccccc}
\hline \multicolumn{3}{c}{ Target relative composition } & \multicolumn{5}{c}{ Film relative composition } \\
\hline$[\mathrm{O}]_{\mathrm{t}}$ & {$[\mathrm{Ge}]_{\mathrm{t}}$} & {$[\mathrm{Nb}]_{\mathrm{t}}$} & {$[\mathrm{Pb}]_{\mathrm{t}}$} & {$[\mathrm{O}]_{\mathrm{f}}$} & {$[\mathrm{Ge}]_{\mathrm{f}}$} & {$[\mathrm{Nb}]_{\mathrm{f}}$} & {$[\mathrm{Pb}]_{\mathrm{f}}$} \\
2.00 & 0.4 & 0.4 & 0.2 & 1.80 & 0.38 & 0.39 & 0.19 \\
\hline
\end{tabular}

The characterization of optical waveguides has been performed at $633 \mathrm{~nm}$ wavelength by using the dark-line prismcoupling configuration [15]. A He-Ne laser beam is focused on the base of an isosceles rutile prism pressed on the film. The incidence angle of the beam on the waveguide is changed until the projection of the propagation constant of the laser beam along the waveguide matches the propagation constant of a guided mode. A dark line is then observed in the reflected spot corresponding to the mode coupled to the waveguide, the effective index of the mode being related to the incidence angle. From the effective indexes of at least two modes, the thickness and the refractive index of the film can be easily and precisely determined. Table 4 shows the thickness and refractive index for all samples. The values of the refractive indexes are very close to that of the bulk samples (2.1137).

Table 4. Refractive index and thicknes of the GPN:Er thin films used in this work.

\begin{tabular}{|c|c|c|}
\hline Thin Film & Thickness & Refractive index \\
\hline GPN:Er ${ }^{3+}(0 \%)$ & $510 \mathrm{~nm}$ & 2.10 \\
\hline GPN: $\operatorname{Er}^{3+}(0.5 \%)$ & $675 \mathrm{~nm}$ & 2.10 \\
\hline GPN:Er ${ }^{3+}(1 \%)$ & $655 \mathrm{~nm}$ & 2.09 \\
\hline GPN:Er ${ }^{3+}(2 \%)$ & $825 \mathrm{~nm}$ & 2.09 \\
\hline GPN: $\operatorname{Er}^{3+}(3 \%)$ & $900 \mathrm{~nm}$ & 2.08 \\
\hline
\end{tabular}

Luminescence measurements were performed at room temperature with a single grating monochromator (focal length $0.22 \mathrm{~m}$ ), an infrared R5509 Hamamatsu photomultiplier, and standard lock-in techniques. The films were excited at $980 \mathrm{~nm}$ with a tunable Ti-sapphire ring laser, and the incident beam formed a $25^{\circ}$ angle with the sample normal. The 
emitted light was collected along the direction perpendicular to the film. Luminescence decay curves at the peak of the emission spectrum were averaged and recorded by a digital oscilloscope.

The emission spectra for the as-deposited samples with different $\mathrm{Er}_{2} \mathrm{O}_{3}$ concentrations were obtained at room temperature by exciting at $980 \mathrm{~nm}$. A broad spectrum is observed in all cases with a main peak at $1530 \mathrm{~nm}$ corresponding to the transition between the ${ }^{4} \mathrm{I}_{13 / 2}$ and ${ }^{4} \mathrm{I}_{15 / 2}$ states of $\mathrm{Er}^{3+}$ ions. The luminescence intensity, which is very weak in the samples with low $\mathrm{Er}^{3+}$ concentration, increases with concentration as the $\mathrm{Er}_{2} \mathrm{O}_{3}$ content in the targets increases from 0.5 to $3 \mathrm{wt} \%$. It is interesting to notice that the as-deposited samples show a measurable luminescence at room temperature. However the lifetime values measured for them, which are single exponentials, are unexpectedly short: $400 \mu \mathrm{s}, 289 \mu \mathrm{s}, 187 \mu \mathrm{s}$, and $87 \mu \mathrm{s}$ for the films doped with $0.5,1,2$, and $3 \mathrm{wt} \%$ respectively. They are one order of magnitude shorter than those observed in the targets, suggesting an important concentration of defects in the films. The films were thus annealed for $1 \mathrm{~h}$ at $600{ }^{\circ} \mathrm{C}$ at atmospheric pressure and cooled down to room temperature. After annealing, an increase in both the luminescence intensity and lifetimes is observed. Figure 3 shows the room temperature emission spectra of the films after annealing. The spectral features of the emission in the annealed films are similar to those observed in the as-deposited films, exception made of the emission intensity which increases by a factor of 30 in the annealed samples. This indicates there are no significant changes in the chemical surrounding of the Er ${ }^{3+}$ ions upon annealing as these changes should affect the Stark splitting and the spectrum peak structure.
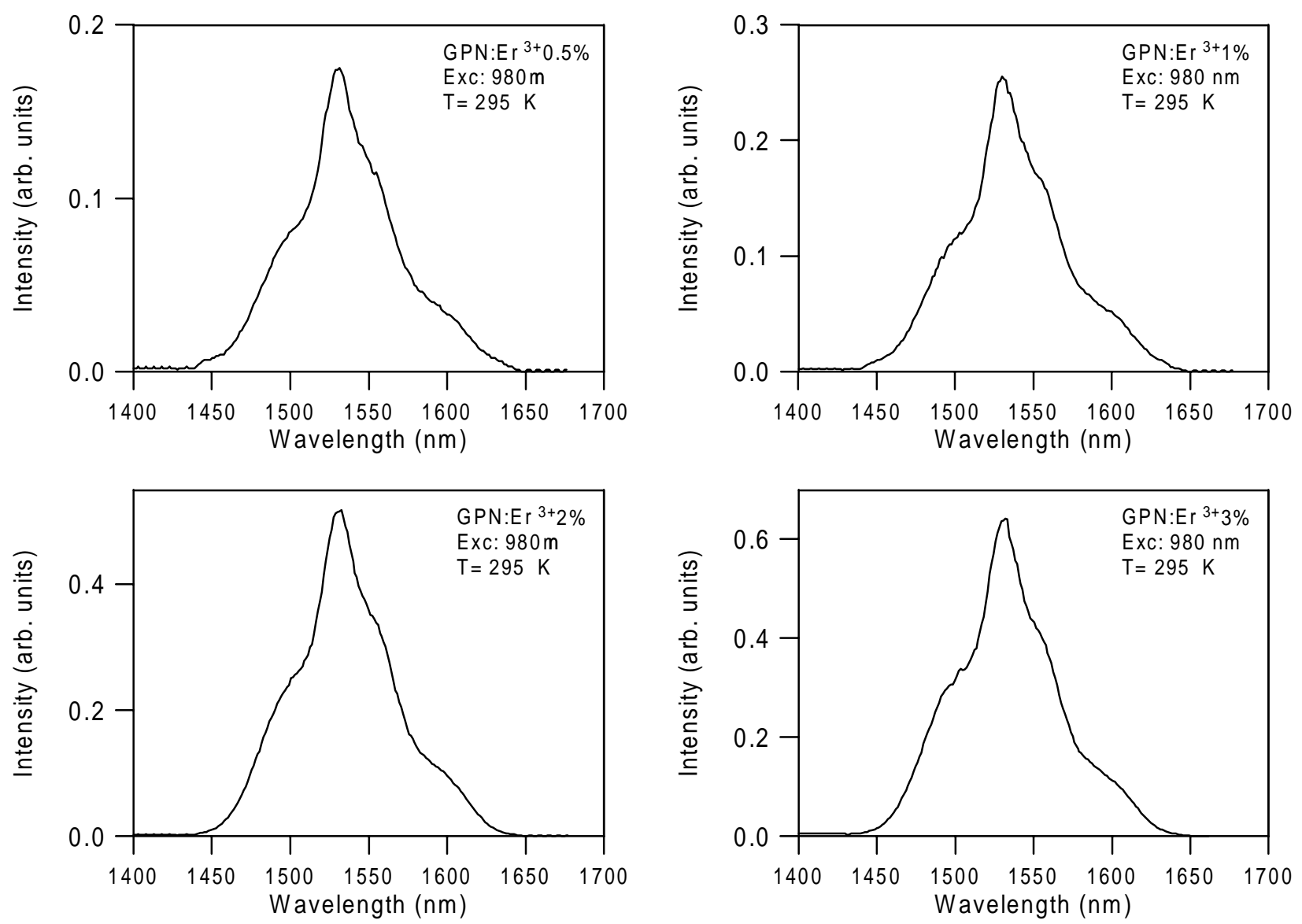

Figure 3. Room temperature emission spectra of $\mathrm{GPN}: \mathrm{Er}^{3+}$ thin films after annealing at $600{ }^{0} \mathrm{C}$ during $1 \mathrm{~h}$. 
The lifetime values also increase upon annealing. The results are shown in Fig. 5, where the decays are shown in a semilogarithmic plot. The lifetime values are $2 \mathrm{~ms}, 1.8 \mathrm{~ms}, 1.5 \mathrm{~ms}$, and $1 \mathrm{~ms}$ for the films with $0.5,1,2$, and $3 \mathrm{wt} \%$ of $\mathrm{Er}_{2} \mathrm{O}_{3}$ respectively. The increase in the lifetimes is related to a decrease of the nonradiative decay channels in the films.

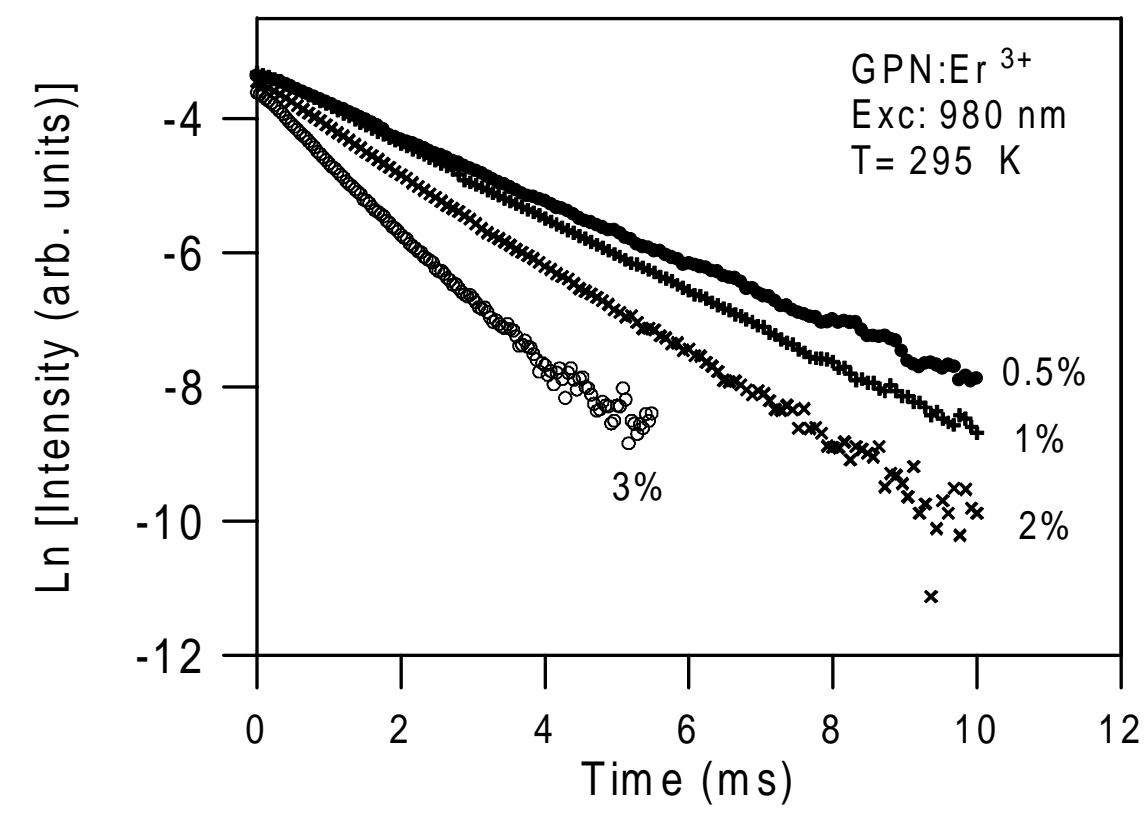

Figure 4. Experimental decays of GPN: $\mathrm{Er}^{3+}$ thin films after annealing at $600{ }^{\circ} \mathrm{C}$ during $1 \mathrm{~h}$.

\section{SUMMARY}

Optically active $\mathrm{Er}^{3+}$-doped GPN thin films with different $\mathrm{Er}_{2} \mathrm{O}_{3}$ concentrations ranging between 0.5 and 3 wt $\%$ have been prepared by pulsed laser deposition with the bulk samples as targets. The film composition is close to that of the targets although the films are slightly oxygen deficient. The as deposited films show the ${ }^{4} \mathrm{I}_{13 / 2} \rightarrow{ }^{4} \mathrm{I}_{15 / 2}$ emission centered around $1530 \mathrm{~nm}$ at room temperature. Annealing allows us to improve the luminescence performances by increasing the lifetimes and intensities of the emission at $1.5 \mu \mathrm{m}$.

\section{ACKNOWLEDGEMENTS}

This work has been supported by the Spanish Government MCYT (MAT2000-1135) and the Basque Country University (UPV 13525/2001). O. Sanz acknowledges the financial support of the Comunidad de Madrid.

\section{REFERENCES}

1. W.H. Dumbaugh and J.C. Lapp, "Heavy-metal oxide glasses,” J. Am. Ceram. Soc. 75, pp. 2315-2325, 1992.

2. D.W. Hall, M.A. Newhouse, N.F. Borrelli, W.H. Dumbaugh, and D.L. Weidman, "Nonlinear optical susceptibilities of high-index glasses," Appl. Phys. Lett. 54, pp. 1293-1295, 1989.

3. J.E Shielby, "Lead Galliate Glasses," J. Am. Ceram. Soc. 71, pp. C-254-C-256, 1988. 
4. A.A. Kharlamov, R.M. Almeida, and J. Heo, "Vibrational spectra and structure of heavy metal oxide glasses," $J$. Non-Cryst. Solids 202, pp. 233-240, 1996.

5. H. Takebe, K. Yoshino, T. Murata, K. Morinaga, J. Hector, W.S. Brocklesby, D.W.Hewak, J. Wang and D.N. Payne, "Spectroscopic properties of $\mathrm{Nd}^{3+}$ and $\mathrm{Pr}^{3+}$ in gallate glasses with low phonon energies," Appl. Opt. 36, pp. 5839-5843, 1997.

6. J. McDougall, D.B. Hollis and M.J.P. Payne, "The $1.82 \mu \mathrm{m}$ emission of $\mathrm{Tm}^{3+}$ in germanium based oxide glass," Phys. Chem. Glasses 36, pp. 52-52, 1995.

7. D.P. Shepherd, D.J.B. Brick, J. Wang, A.C. Tropper, D.C. Hanna, G. Kakarantzas and P.D. Twonsend, "1.9- $\mu \mathrm{m}$ operation of a Tm:lead germanate glass waveguide laser," Opt. Lett. 19, pp. 954-956, 1994.

8. B.R. Judd, "Optical absorption intensities of rare-earth ions," Phys. Rev. 127, pp. 750-761, 1962.

9. G.S. Ofelt, "Intensities of crystal spectra of rare-earth ions," J. Chem. Phys. 37, pp. 511-520, 1962.

10. W.T. Carnall, P.R. Fields, K. Rajnak, "Spectral Intensities of the trivalent lanthanides and actinides in solution. II. $\mathrm{Pm}^{3+}, \mathrm{Sm}^{3+}, \mathrm{Eu}^{3+}, \mathrm{Gd}^{3+}, \mathrm{Tb}^{3+}, \mathrm{Dy}^{3+}$, and $\mathrm{Ho}^{3+}$, "J. Chem. Phys. 49, pp. 4412-4423, 1968.

11.M. Wachtler, A. Speghini, K. Gatterer, H.P. Fritzer, D. Ajò, and M. Bettinelli, "Optical properties of rare-earth ions in lead-germanate glasses," J. Am. Ceram. Soc. 81, pp. 2045-2052, 1998.

12. Z. Pan, S.H. Morgan, K. Dyer, A. Ueda, and H. Liu, "Host-dependent optical transitions of $\mathrm{Er}^{3+}$ ions in leadgermanate and lead-tellurium-germanate glasses," J. Appl. Phys. 79, pp. 8906-8913, 1996.

13. M.J. Weber, "Probabilities for radiative and nonradiative decay of $\mathrm{Er}^{3+}$ in $\mathrm{LaF}_{3}$," Phys. Rev. 157, pp. 262-272, 1967.

14. M.J. Weber, D.C. Ziegler, and C.A. Angell, "Tailoring stimulated emission cross sections of $\mathrm{Nd}^{3+}$ laser glass: Observation of large cross sections for $\mathrm{BiCl}_{3}$ glasses," J. Appl. Phys. 53, pp. 4344-4350, 1982.

15. S. Pelli and G.C. Righini, "Characterization and Modelling of Optical Waveguides", Advances in Integrated Optics, edited by M. Martelluci, A.N. Chester, and M. Bertolotti (New York:Plenum), pp. 1-20, 1994. 